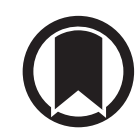

CrossMark

\title{
No indication of insulin resistance in idiopathic pulmonary arterial hypertension with preserved physical activity
}

\author{
To the Editor:
}

There is growing interest in metabolic profiling in pulmonary arterial hypertension (PAH) due to current findings suggesting significant metabolic changes causing pulmonary arterial remodelling and linking PAH to insulin resistance [1]. Such findings may have major impact on future diagnostic and therapeutic strategies for PAH. However, most studies have enrolled patients with severe disease whose reduced physical activity may have a profound effect on insulin sensitivity.

Insulin resistance is associated with endothelial dysfunction, impaired angiogenesis, atherosclerosis, cardiomyopathy or myocardial fibrosis [2,3]. In 2009, an elegant study suggested that insulin resistance is quite common in PAH and associated with a poor survival [4]. This was in line with findings in the apoE knockout mouse developing both insulin resistance and PAH [5]. Subsequent studies showed that glucose intolerance is a common feature in idiopathic PAH (IPAH) $[6,7]$ and recently this was explained by a metabolic pattern of lipid-related insulin resistance [8]. Unfortunately, these studies did not investigate whether insulin resistance caused the development of PAH or was a consequence of PAH, e.g. due to loss of physical activity; furthermore, they relied on surrogate markers of insulin resistance rather than direct assessment of insulin sensitivity.

Though surrogate markers of insulin resistance (TG/HDL-C, HbAlc, HOMA-IR) are widely accepted and technically simple to obtain, there is some discussion about their validity for the assessment of insulin sensitivity in individual patients. The technical gold standard is the hyperinsulinaemic-euglycaemic Botnia clamp investigation. This is an invasive, time-consuming technique requiring dedicated equipment and trained staff $[9,10]$.

We assessed insulin sensitivity by employing simultaneous pairwise matched-control Botnia clamp investigations, and found no indication of insulin resistance in patients with severe idiopathic PAH and preserved physical activity.

The study was approved by the institutional ethical committee of the Medical University of Graz, and registered at https://clinicaltrials.gov/ as NCT03584607. All patients participated after written informed consent and approval of the local ethics committee.

Five non-diabetic normal weight IPAH patients and their age-, sex- and body composition-matched non-diabetic healthy controls were invited to our clinic on the same day, where all investigations on such a patient-control pair were carried out in parallel. The IPAH patients were selected based on interviews showing that they had no major limitations in any daily activity, apart from doing sports. The controls were identified from the Medical University of Graz Clinical Trials Unit database using the Phoenix Clinical Trial Management System. In all selected controls, pulmonary hypertension was excluded by means of echocardiography. Two control subjects were treated for systemic hypertension, and two for hypothyroidism (control 1: candesartan, levothyroxine; control 2: levothyroxine; control 3: none; control 4: none; control 5: candesartan, nebivolol, allopurinol). All IPAH patients were on PAH therapy (patient \#1 (World Health Organization functional class (WHO FC) I, time from diagnosis:

@ERSpublications

Insulin resistance might not be a primary cause of severe remodelling of the small pulmonary arteries in idiopathic PAH http://bit.ly/3c8elot

Cite this article as: Nagy BM, Kovacs G, Tornyos A, et al. No indication of insulin resistance in idiopathic pulmonary arterial hypertension with preserved physical activity. Eur Respir J 2020; 55: 1901228 [https:// doi.org/10.1183/13993003.01228-2019]. 
111 months): amlodipine, macitentan; patient \#2 (WHO FC II, time from diagnosis: 228 months): amlodipine, macitentan, inhaled iloprost; patient \#3 (WHO FC II, time from diagnosis: 178 months): sildenafil, macitentan; patient \#4 (WHO FC I, time from diagnosis: 19 months): amlodipine; patient \#5 (WHO FC II, time from diagnosis: 20 months): macitentan, inhaled lloprost). All participants underwent dual-energy X-ray absorptiometry measurement to estimate whole body adipose tissue distribution. Scan areas were analysed to determine lean mass, fat mass, bone mineral content and total body fluid percentage. The subjects received standardised nutrition (Fresenius Kabi) according to the predicted calorie demand (Harris-Benedict equation) on the day before the study, and then were fasted for $20 \mathrm{~h}$. On the next day dynamic insulin regulation was tested with a combined intravenous glucose tolerance test (IVGTT) and the hyperinsulinaemic-euglycaemic clamp (Botnia clamp) assessing both insulin secretion and insulin sensitivity [9]. Baseline samples were obtained at standardised times, and subjects were given an intravenous $20 \%$ glucose bolus $(0.3 \mathrm{~g}$ per $\mathrm{kg}$ body weight $)$ at the start of the Botnia clamp (0 min). Blood samples for plasma glucose, insulin, and C-peptide were obtained at $-10,0,2,4,6,8,10$, 20, 30, 40, 50 and $60 \mathrm{~min}$. At $60 \mathrm{~min}$, the hyperinsulinaemic-euglycaemic clamp was started to determine insulin sensitivity. A priming dose of insulin $\left(3 \mathrm{IU} \cdot \mathrm{m}^{-2}\right.$ ) followed by an infusion $\left(40 \mathrm{mU} \cdot \mathrm{m}^{-2} \cdot \mathrm{min}^{-1}\right)$ of short-acting human insulin was continuously infused into a peripheral vein for $120 \mathrm{~min}$. Blood glucose level was held constant (clamped at $100 \pm 10 \mathrm{mg} \cdot \mathrm{dL}^{-1}$ ) by intravenous infusion of $20 \%$ glucose, using the negative feedback principle. Blood samples for measurement of plasma glucose and insulin concentrations were obtained at 5- and 30-min intervals, respectively, throughout the clamp. Glucose concentrations were measured with the Super GL compact analyser (Hitado), insulin and C-peptide levels with chemiluminescence on an ADVIA Centaur system (Siemens). Differences between patients and their matched controls were tested with the 2 -sided exact test. $\mathrm{p}<0.05$ was considered statistically significant.

We enrolled five pairs of IPAH patients (mean \pm SD pulmonary arterial pressure $40 \pm 8 \mathrm{mmHg}$, cardiac index 2.6 $\pm 0.6 \mathrm{~L} \cdot \mathrm{min}^{-1} \cdot \mathrm{m}^{-2}$, pulmonary vascular resistance $7.2 \pm 3.6 \mathrm{WU}$, right atrial pressure $5 \pm 3 \mathrm{mmHg}$, pulmonary arterial wedge pressure $8 \pm 2 \mathrm{mmHg}$ ) and their healthy controls (female sex $80 \%$ versus $80 \%$, age $58.7 \pm 8.0$ years versus $59.9 \pm 7.5$ years, 6-min walk distance $487.8 \pm 59.7 \mathrm{~m}$ versus $486.8 \pm 69.9 \mathrm{~m}$, N-terminal pro B-type natriuretic peptide (NT-proBNP) $327.0 \pm 416.0 \mathrm{pg} \cdot \mathrm{mL}^{-1}$ versus $82.2 \pm 40.8 \mathrm{pg} \cdot \mathrm{mL}^{-1}$, forced expiratory volume in $1 \mathrm{~s} 100.6 \pm 8.9 \%$ pred versus $109.7 \pm 8.2 \%$ pred, diffusing capacity of the lung for carbon monoxide corrected for haemoglobin $70.4 \pm 10.4 \%$ pred versus $91.7 \pm 14.7 \%$ pred; $\mathrm{p}=0.032$ ) over a period of 10 months. IPAH patients displayed lower systemic blood pressure (systolic blood pressure $113.6 \pm 13.4 \mathrm{mmHg}$ versus $137.6 \pm 10.01 \mathrm{mmHg}$; $\mathrm{p}=0.016$; diastolic blood pressure $70.4 \pm 6.1 \mathrm{mmHg}$ versus $88.6 \pm 9.4 \mathrm{mmHg} ; \mathrm{p}=0.016$ ) and higher NT-proBNP as compared to their controls, but no other significant differences, apart from pulmonary haemodynamics. The two groups were comparable in terms of physical characteristics (BMI $24.0 \pm 2.5 \mathrm{~kg} \cdot \mathrm{m}^{-2}$ versus $25.3 \pm 4.4 \mathrm{~kg} \cdot \mathrm{m}^{-2}$, body fat percentage $35.8 \pm 5.6 \%$ versus $34.7 \pm 9.9 \%$, trunk fat mass/total fat mass: $0.47 \pm 0.1$ versus $0.51 \pm 0.1)$, fasting blood glucose levels $\left(84.4 \pm 2.7 \mathrm{mg} \cdot \mathrm{dL}^{-1}\right.$ versus $\left.83.0 \pm 6.1 \mathrm{mg} \cdot \mathrm{dL}^{-1}\right)$, HbAlc levels $\left(36.4 \pm 2.1 \mathrm{mmol} \cdot \mathrm{mol}^{-1}\right.$ versus $34.4 \pm 2.3 \mathrm{mmol} \cdot \mathrm{mol}^{-1}$ ) and TG/HDL-C ratio (1.1 \pm 0.3 versus $\left.1.9 \pm 1.0\right)$. Both groups displayed normal efficacy of glycaemic control (HOMA index $0.84 \pm 0.2$ versus $1.09 \pm 0.6$ ). The Botnia clamp measurements

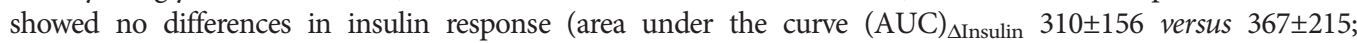
$\mathrm{p}=0.69 ; \mathrm{AUC}_{\Delta \mathrm{C} \text {-peptide }} 26.1 \pm 6.9$ versus $32.2 \pm 15.1, \mathrm{p}=0.69$ and disposition index $\mathrm{M}_{\mathrm{M}}$ value ${ }^{*} \mathrm{AUC} \Delta \mathrm{Insulin} 3828 \pm 2058$ versus $4669 \pm 1613 ; \mathrm{p}=0.53$ ) or insulin sensitivity (figure $1 \mathrm{~b}$ ) in any of the IPAH patients when compared to their healthy controls and also the comparison of the groups showed no significant differences. In IPAH, the whole-body glucose disposal capacity in response to insulin infusion showed the same characteristics as in healthy controls (figure 1c).

We applied the gold standard Botnia clamp method to evaluate insulin sensitivity in IPAH patients with severely elevated pulmonary arterial pressure but well preserved right ventricular function and normal daily activity. The Botnia clamp determines the metabolic clearance rate of glucose upon infused insulin, and currently represents the most accurate method to assess insulin sensitivity. Decreased insulin sensitivity defines insulin resistance.

In this study we detected no indication of insulin resistance in patients characterised by manifest IPAH but no major limitations in their daily physical activity. This does not rule out the possibility that metabolic dysregulation may occur when the disease causes decreased physical activity and that this dysregulation worsens the pulmonary vascular remodelling. However, our finding speaks against the actual hypothesis that insulin resistance represents an important primary cause for severe remodelling of the small pulmonary arteries leading to IPAH.

As a limitation, our small cohort does not represent the full range of IPAH patients, and responders to calcium channel blockers have been overrepresented. The application of PAH medications might have influenced insulin sensitivity. We have studied a prevalent population of long-term survivors and results might be different in an incident population. It is possible that patients suffering from more severe disease 
a)
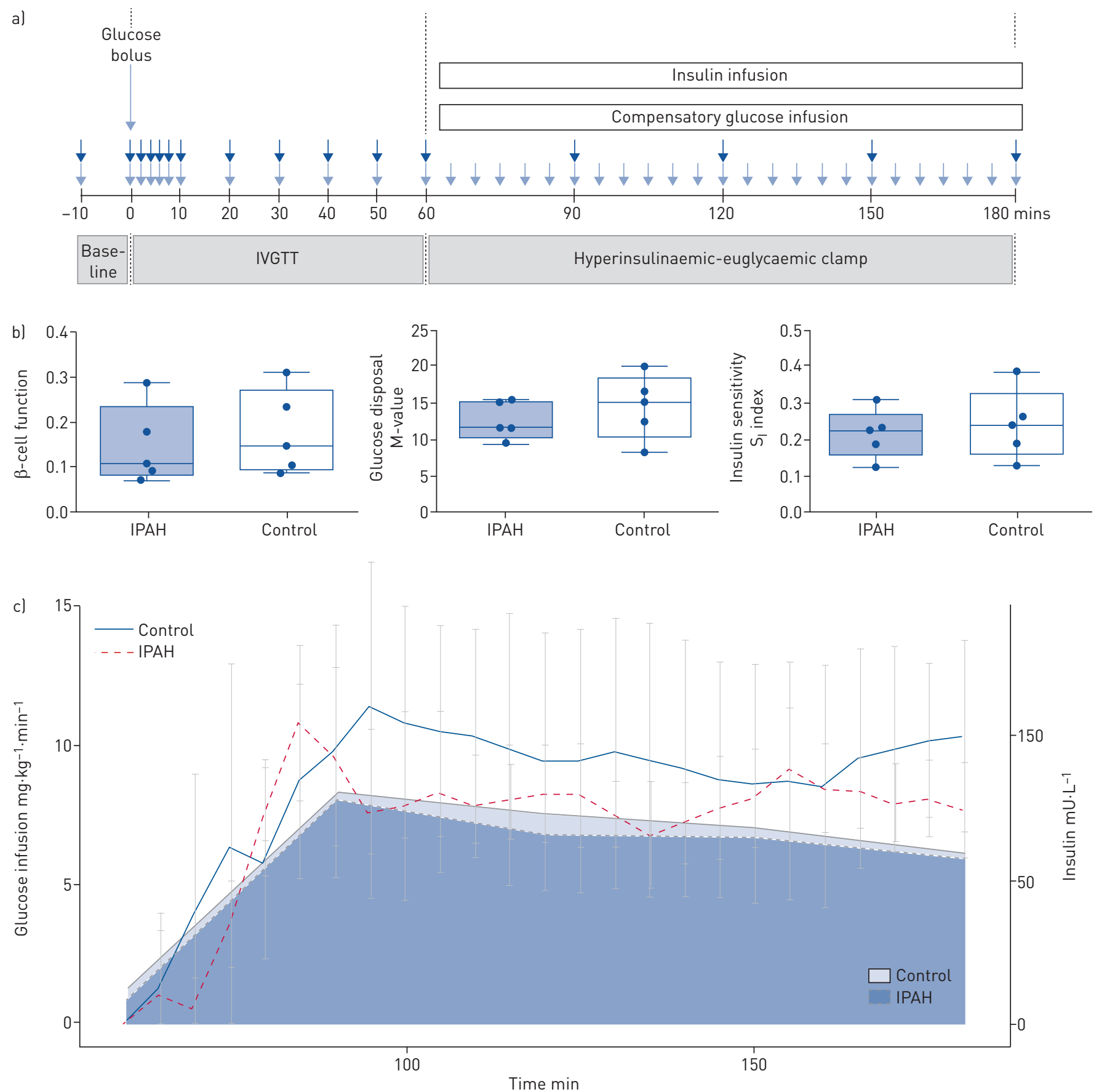

FIGURE 1 Insulin sensitivity in pulmonary hypertension. a) Representative scheme of the Botnia clamp protocol. Small arrows indicate blood sampling for assessing glucose (light) or blood insulin and C-peptide (dark blue) levels. b) $\beta$-cell function: calculated as plasma insulin incremental area under the curve (AUC) over plasma glucose incremental AUC during the first 10 min of intravenous glucose tolerance test (IVGTT). Glucose disposal: or "M value", amount of metabolised glucose; calculated by glucose infusion rate per kg lean body weight during steady state period corrected by plasma glucose space-correction. Insulin sensitivity: or "S, Index", the quantity of glucose metabolised per unit of plasma insulin concentration, calculated by the steady state rate of exogenous glucose infusion divided by the insulin concentration during the same time period $\left(\mathrm{mg} \cdot \mathrm{kg}^{-1} \cdot \mathrm{min}^{-1}\right.$ per $\left.\mathrm{mU} \cdot \mathrm{L}^{-1}\right)$. c) Glucose infusion rate in idiopathic pulmonary arterial hypertension (IPAH) and control subjects (lines) in relation to their corresponding mean insulin levels (blue areas). $n=5$.

causing decreased physical activity and overweight may show different results. However, such changes in insulin sensitivity would be considered as secondary effects of the disease and not as an underlying cause of pulmonary hypertension.

In conclusion, this study does not support insulin resistance to be a primary cause of pulmonary vascular remodelling in IPAH. 
Bence M. Nagy ${ }^{1}$, Gabor Kovacs ${ }^{1,2}$, Adrienn Tornyos ${ }^{1,3}$, Eva Svehlikova ${ }^{4}$, Vasile Foris ${ }^{1,2}$, Chandran Nagaraj $^{1}$, Grazyna Kwapiszewska $^{1,5}$, Thomas R. Pieber ${ }^{4}$, Andrea Olschewski ${ }^{1,6}$ and Horst Olschewski ${ }^{1,2}$

${ }^{1}$ Ludwig Boltzmann Institute for Lung Vascular Research, Graz, Austria. ${ }^{2}$ Division of Pulmonology, Dept of Internal Medicine, Medical University of Graz, Graz, Austria. ${ }^{3}$ Division of General Radiology, Dept of Radiology, Medical University of Graz, Graz, Austria. ${ }^{4}$ Division of Endocrinology and Diabetology, Dept of Internal Medicine, Medical University of Graz, Graz, Austria. ${ }^{5}$ Otto Loewi Center, Medical University of Graz, Graz, Austria. ${ }^{6}$ Division of Special Anaesthesiology, Pain and Intensive Care Medicine, Dept of Anaesthesiology and Intensive Care Medicine, Medical University of Graz, Graz, Austria.

Correspondence: Bence M. Nagy, Ludwig Boltzmann Institute, Lung Vascular Research, Neue Stiftingtalstrasse 6, Graz A-8010, Austria. E-mail: bence.nagy@lvr.lbg.ac.at

Received: 11 July 2019 | Accepted after revision: 15 Feb 2020

This study was registered at Clinicaltrials.gov as NCT03584607.

Conflict of interest: B.M. Nagy has nothing to disclose. G. Kovacs reports personal fees and non-financial support from Actelion, Bayer, GSK, MSD, Boehringer Ingelheim, Novartis and Chiesi, non-financial support from VitalAire and AOP, outside the submitted work. A. Tornyos has nothing to disclose. E. Svehlikova has nothing to disclose. V. Foris reports non-financial support from Actelion, AstraZeneca, Novartis, BMS and Chiesi, personal fees for lectures from Bayer and Gerrot Lannach, personal fees for advisory board work and non-financial support from Boehringer Ingelheim, personal fees for advisory board work from GSK, personal fees for advisory board work and lectures, and non-financial support from MSD, outside the submitted work. C. Nagaraj has nothing to disclose. G. Kwapiszewska has nothing to disclose. T.R. Pieber has nothing to disclose. A. Olschewski has nothing to disclose. H. Olschewski reports personal fees and non-financial support from Bayer, MSD, Pfizer and Novartis, grants, personal fees and non-financial support from Actelion, grants from Inventiva, personal fees from Bellerophon, outside the submitted work; and is part time employee of Ludwig Boltzmann Institute for Lung Vascular Research, Graz, Austria.

\section{References}

1 Culley MK, Chan SY. Mitochondrial metabolism in pulmonary hypertension: beyond mountains there are mountains. J Clin Invest 2018; 128: 3704-3715.

2 Muniyappa R, Montagnani M, Koh KK, et al. Cardiovascular actions of insulin. Endocr Rev 2007; 28: 463-491.

3 Russo I, Frangogiannis NG. Diabetes-associated cardiac fibrosis: cellular effectors, molecular mechanisms and therapeutic opportunities. J Mol Cell Cardiol 2016; 90: 84-93.

4 Zamanian RT, Hansmann G, Snook S, et al. Insulin resistance in pulmonary arterial hypertension. Eur Respir J 2009; 33: 318-324.

5 Hansmann G, Wagner RA, Schellong S, et al. Pulmonary arterial hypertension is linked to insulin resistance and reversed by peroxisome proliferator-activated receptor-gamma activation. Circulation 2007; 115: 1275-1284.

6 Pugh ME, Robbins IM, Rice TW, et al. Unrecognized glucose intolerance is common in pulmonary arterial hypertension. J Heart Lung Transplant 2011; 30: 904-911.

7 Heresi GA, Malin SK, Barnes JW, et al. Abnormal glucose metabolism and high-energy expenditure in idiopathic pulmonary arterial hypertension. Ann Am Thorac Soc 2017; 14: 190-199.

8 Hemnes AR, Luther JM, Rhodes CJ, et al. Human PAH is characterized by a pattern of lipid-related insulin resistance. JCI Insight 2019; 4: 123611.

9 DeFronzo RA, Tobin JD, Andres R. Glucose clamp technique: a method for quantifying insulin secretion and resistance. Am J Physiol 1979; 237: E214-E223.

10 Tripathy D, Wessmann Y, Gullström M, et al. Importance of obtaining independent measures of insulin secretion and insulin sensitivity during the same test: results with the Botnia clamp. Diabetes Care 2003; 26: 1395-1401. 